\title{
A case of primary acquired gastric outlet obstruction (Jodhpur disease): Rare but easily treatable cause of failure to thrive / growth retardation
}

\author{
Kiran Khedkar ${ }^{1}$, *Sachin Gajanan Damke ${ }^{2}$, Sham Lohiya ${ }^{3}$, Meenakshi Yeola ${ }^{4}$, Richa Choudhary ${ }^{3}$ \\ Sri Lanka Journal of Child Health, 2021; 50(4): 721-723 \\ DOI: http://doi.org/10.4038/sljch.v50i4.9897 \\ (Keywords: Jodhpur Disease, Non-bilious vomiting, Gastric outlet obstruction, Failure to thrive)
}

\section{Introduction}

Failure to gain weight is primarily due to inadequate calorie intake but may also be due to inadequate absorption of calories or excess calorie expenditure ${ }^{1}$. Gastric outlet obstruction (GOO) is an uncommon condition after the first few months of life where idiopathic hypertrophic pyloric stenosis is an important cause. In children, causes of GOO are pyloric web, pyloric atresia, peptic ulcer, pyloric stricture and rarely primary acquired GOO, also known as Jodhpur disease ${ }^{2}$. Jodhpur disease is a rare acquired structural abnormality of the gastrointestinal tract of unknown aetiology and up to date very few cases have been reported. We report a child with failure to thrive who was diagnosed as Jodhpur disease and underwent surgery.

\section{Case report}

A 7-year-old girl presented with a history of recurrent vomiting for three years. Vomiting was non bilious and contained food which was ingested 3 to 4 days back. After feeding, she complained of fullness in the left hypochondrium and sometimes pain in the right hypochondrium. In view of above symptoms, child was seen by many doctors and was finally referred to a paediatric gastroenterologist. Ultrasonography (USG) revealed a dilated stomach with diffuse circumferential wall thickening, involving the gastric pylorus, a gall bladder polyp $9.8 \mathrm{~mm} \times 6 \mathrm{~mm}$ in size, a liquid gastric emptying rate of $18.3 \%$ and a gastric motility index of 2.24 . On upper gastro-intestinal endoscopy, the smallest size scope could not be negotiated beyond the pylorus.

\footnotetext{
${ }^{1}$ Assistant Professor, Paediatric Surgery,

${ }^{2}$ Professor, ${ }^{3}$ Associate Professor Department of Paediatrics, ${ }^{4}$ Professor and Head, Department of Surgery, Jawaharlal Nehru Medical College, Datta Meghe Institute of Medical Sciences, India *Correspondence: drsachindjnme@gmail.com
}

https://orcid.org/0000-0002-2517-1995 (Received on 18 September 2020: Accepted after revision on 16 October 2020)

The authors declare that there are no conflicts of interest.

Personal funding was used for the project.

Open Access Article published under the Creative Commons Attribution CC-BY cc) (7) License
Patient was then referred for surgical management. She had two episodes of foreign body impaction in the lower oesophagus two years prior to development of the above symptoms and these were removed via endoscopy.

On examination, patient had stable vital signs. Her height was $98 \mathrm{~cm}$, weight $12 \mathrm{~kg}$ and body mass index $12.5 \mathrm{~kg} / \mathrm{m}^{2}$ which falls below 2 standard deviations. After feeding, the child was noticed to have abdominal fullness in the epigastric region with visible gastric peristalsis (Figure 1).

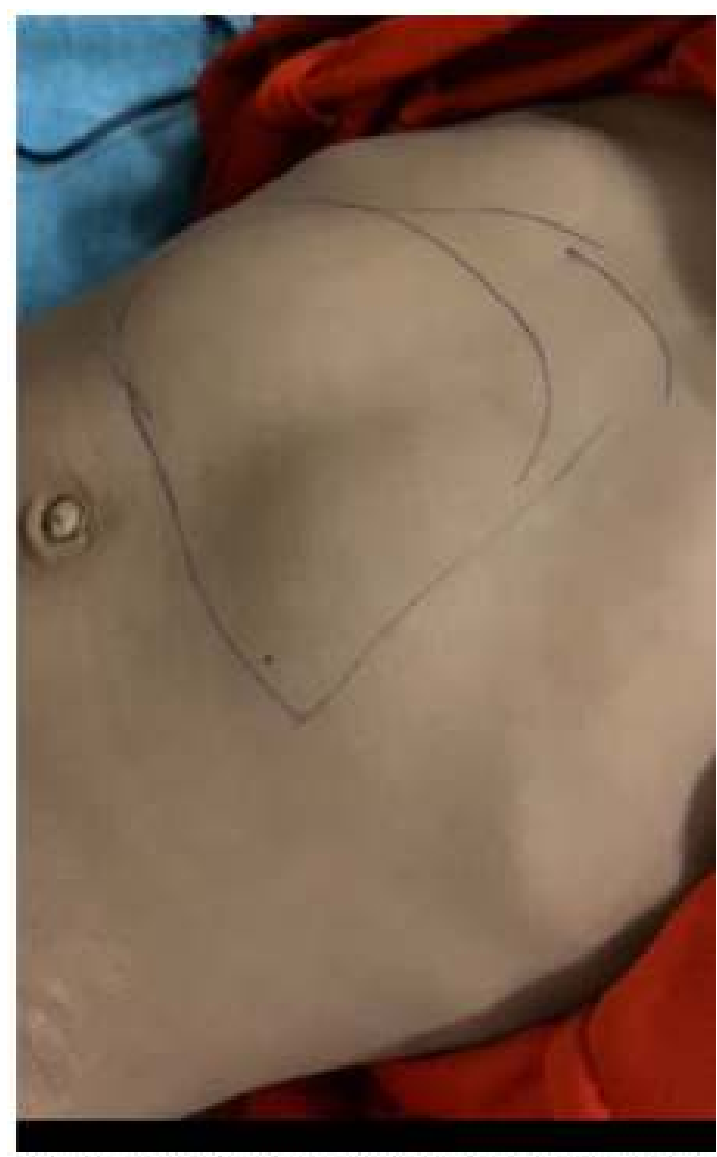

Figure 1: Abdominal fullness in epigastric region

Blood investigations were within normal limits. Contrast enhanced computed tomography (CECT) scan of the abdomen showed a grossly dilated stomach suggestive of GOO (Figure 2). Pyloroplasty was planned for this child and so she was kept nil by mouth and nasogastric tube inserted and gastric lavage was done to remove all food residue. 


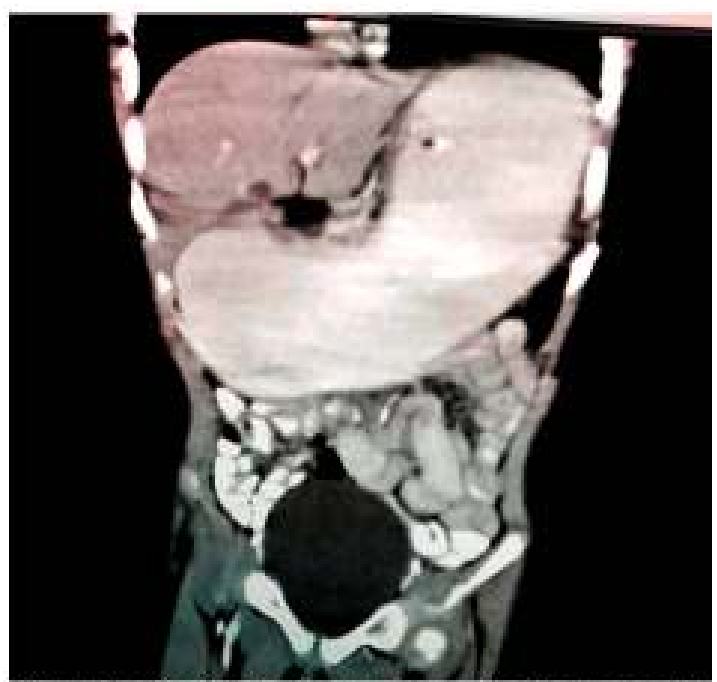

Figure 2: Contrast enhanced computed tomography of abdomen showing grossly dilated stomach

Laparotomy was done. Intra-operative examination revealed a huge dilated stomach with thickening noticed at the pylorus. Cholecystectomy was done first and then the pylorus was opened longitudinally. Thickening of the pyloric wall was seen and the absence of an obstructing valve or diaphragm was confirmed (Figure 3). Heineke Mikulicz pyloroplasty was done using interrupted 3-0 vicryl sutures. The child tolerated the surgery well. Oral feeds were started on the $5^{\text {th }}$ post-operative day, which she tolerated well and the child was discharged on $7^{\text {th }}$ post-operative day. On follow up, child was tolerating feeds well and gaining weight. Gall bladder was sent for histopathology and was suggestive of an inflammatory polyp.

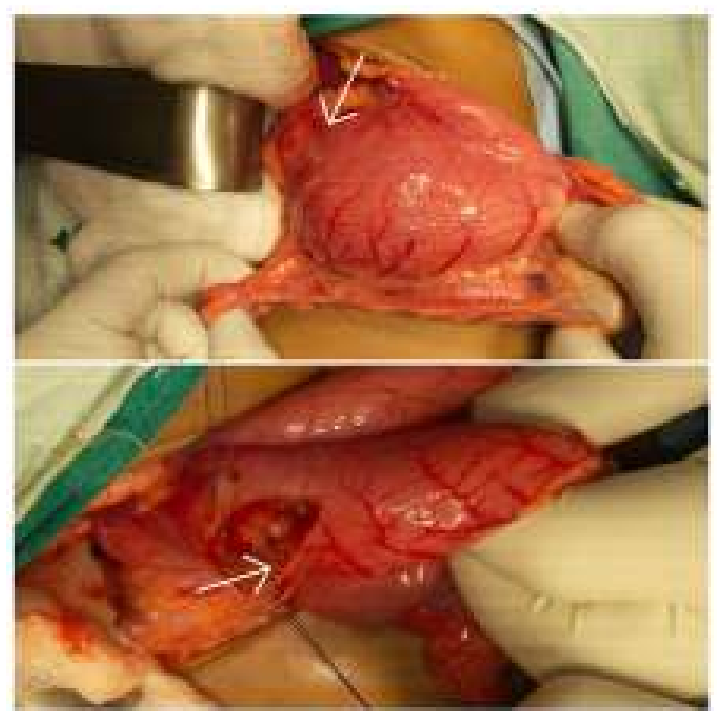

Figure 3: showing thickening of pyloric wall and absence of obstructing vahe or diaphragm

\section{Discussion}

Obstruction at the pyloric end leads to GOO where the child presents with recurrent non-bilious vomiting after feeds ${ }^{2}$. Primary acquired GOO is called Jodhpur disease as the first case was reported from Jodhpur, India ${ }^{3}$. The reported incidence is 1 in 100,000 with a slight predilection for males ${ }^{4}$. The mean age of diagnosis is 2.9 years, the range being one month to six years of age. As the name suggests the precise aetiology is not well understood. A dietary factor was thought to be the cause because most cases were reported from North India. Another theory suggests lack of nitric oxide synthase which causes failure of pyloric smooth muscles to relax leading to neuromuscular incordination and GOO. Another theory is that the cause could be an abnormality of the interstitial cell of Cajal that acts as an electrical pacemaker of the gastrointestinal smooth muscle cells ${ }^{5}$. Heineke-Mikulicz pyloroplasty is the treatment of choice for Jodhpur disease.

Our case was a girl from Central India. She also had complaints of right hypochondrial pain and the USG showed a gall bladder polyp. We did not find any association of Jodhpur disease with gall bladder polyp in the literature and it appears to be a coincidental finding. As the patient had recurrent upper abdominal pain and the size of polyp was approximately $1 \mathrm{~cm}$, cholecystectomy was done in the same setting. Cholecystectomy is indicated if the gall bladder polyps are more than $1 \mathrm{~cm}$ in size or are symptomatic.

We report this case as the child was symptomatic for nearly three years and a simple surgery was needed for the treatment. Although Jodhpur disease is rare, it should not be missed as it can be easily diagnosed with contrast radiography which is available in most parts of the world. The condition is easily amenable to treatment, which can prevent growth retardation / failure to thrive.

Jodhpur disease is a rare entity with presentation as GOO. A high degree of clinical suspicion is necessary in preschool children presenting with recurrent non-bilious vomiting. Upper gastrointestinal contrast study is diagnostic and should be done as early as possible in evaluation of recurrent vomiting in children. Surgery is the mainstay of treatment and early diagnosis and treatment can prevent malnutrition and growth retardation in the affected child.

\section{References}

1. Homan GJ. Failure to Thrive: A Practical Guide. American Family Physician 2016; 94(4): 295-9.

2. Kajal P, Bhutani N, Kadian YS. Primary acquired gastric outlet obstruction 
(Jodhpur disease). Journal of Pediatric Surgery Case Reports 2019; 40: 6-9.

https://doi.org/10.1016/j.epsc.2018.09.009

3. Sharma KK, Agrawal P, Toshniwal H. Acquired gastric outlet obstruction during infancy and childhood: a report of five unusual cases. Journal of Pediatric Surgery 1997; 32(6): 928-30. https://doi.org/10.1016/S00223468(97)90 654-0

4. Tayal N, Kadian YS, Ahari P, Kadian A. Jodhpur Disease (Primary acquired gastric outlet obstruction in infancy and childhood): A rare case. IOSR-JDMS 2018; 17(2): 7-8.
5. Nazir Z, Arshad M. Late-onset primary gastric outlet obstruction--an unusual cause of growth retardation. Journal of Pediatric Surgery 2005; 40(6):e13-e16.

https://doi.org/10.1016/j.jpedsurg.2005.03 .030

PMid: 15991158 